Western University

Scholarship@Western

Brain and Mind Institute Researchers'

Publications

Brain and Mind Institute

$11-1-2016$

\title{
The serotonin transporter promoter polymorphism moderates the continuity of behavioral inhibition in early childhood.
}

Victoria C Johnson

Katie R Kryski

Haroon I Sheikh

Heather J Smith

Shiva M Singh

See next page for additional authors

Follow this and additional works at: https://ir.lib.uwo.ca/brainpub

Part of the Neurosciences Commons, and the Psychology Commons

Citation of this paper:

Johnson, Victoria C; Kryski, Katie R; Sheikh, Haroon I; Smith, Heather J; Singh, Shiva M; and Hayden, Elizabeth P, "The serotonin transporter promoter polymorphism moderates the continuity of behavioral inhibition in early childhood." (2016). Brain and Mind Institute Researchers' Publications. 208.

https://ir.lib.uwo.ca/brainpub/208 


\section{Authors}

Victoria C Johnson, Katie R Kryski, Haroon I Sheikh, Heather J Smith, Shiva M Singh, and Elizabeth P Hayden 


\title{
The serotonin transporter promoter polymorphism moderates the continuity of behavioral inhibition in early childhood
}

\author{
VICTORIA C. JOHNSON, KATIE R. KRYSKI, HAROON I. SHEIKH, HEATHER J. SMITH, SHIVA M. SINGH, \\ AND ELIZABETH P. HAYDEN \\ University of Western Ontario
}

\begin{abstract}
Persistently elevated behavioral inhibition (BI) in children is a marker of vulnerability to psychopathology. However, little research has considered the joint influences of caregiver and child factors that may moderate the continuity of BI in early childhood, particularly genetic variants that may serve as markers of biological plasticity, such as the serotonin transporter linked polymorphic region (5-HTTLPR). We explored this issue in 371 preschoolers and their caregivers, examining whether parent characteristics (i.e., overinvolvement or anxiety disorder) and child 5-HTTLPR influenced the continuity of BI between ages 3 and 5. Measures were observational ratings of child BI, observational and questionnaire measures of parenting, and parent interviews for anxiety disorder history, and children were genotyped for the 5-HTTLPR. Parent factors did not moderate the association between age 3 and age 5 BI; however, child BI at age 3 interacted with children's 5-HTTLPR variants to predict age $5 \mathrm{BI}$, such that children with at least one copy of the short allele exhibited less continuity of $\mathrm{BI}$ over time relative to children without this putative plasticity variant. Findings are consistent with previous work indicating the $5-H T T L P R$ short variant increases plasticity to contextual influences, thereby serving to decrease the continuity of BI in early childhood.
\end{abstract}

Children show tremendous individual differences in emotional reactivity and self-regulation (Rothbart, Ahadi, \& Evans, 2000; Rothbart \& Derryberry, 1981). Such differences fall under the rubric of temperament, and have been associated with an array of positive and negative outcomes across development in domains such as mental health, physical health, and psychosocial functioning (e.g., Anzman-Frasca, Stifter, \& Birch, 2012; Clauss \& Blackford, 2012; Gest, 1997; Rothbart, 1989; Rothbart et al., 2000). In particular, there has been great interest on the part of developmental psychopathologists in the temperamental trait behavioral inhibition (BI), the tendency to exhibit heightened fear responses and reticence when confronted with novelty (e.g., GarciaColl, Kagan, \& Reznick, 1984; Kagan, Reznick, Clark, Snidman, \& Garcia-Coll, 1984). The current study investigated a select array of factors that may influence the continuity of BI in early childhood.

The study of BI and its continuity has practical relevance given its implications for children's socioemotional functioning and mental health outcomes. More specifically, although children with high BI are more cooperative, have better attitudes toward school, and greater school competence, they also have poorer quality social relationships (e.g., Chen, Chen, Li, \& Wang, 2009; Gest, 1997; Graham \& Coplan,

This research was supported by the Canadian Institutes of Health Research and the Children's Health Research Institute.

Address correspondence and reprint requests to: Elizabeth P. Hayden, Westminster Hall, 361 Windermere Road, London, ON N6A 3K7, Canada; E-mail: ehayden@uwo.ca.
2012; Hirshfeld-Becker et al., 2007; Izard, Schultz, Fine, Youngstrom, \& Ackerman, 1999; Roswell \& Coplan, 2013). In addition, BI has been widely implicated in vulnerability to internalizing and other disorders (e.g., Lahat, Hong, \& Fox, 2011; Oppenheimer, Hankin, Young, \& Smolen, 2013), including social anxiety disorder (e.g., Gladstone, Parker, Mitchell, Wilhelm, \& Malhi, 2005; Hirshfeld-Becker et al., 2008; Rotge et al., 2011), panic disorder (Rosenbaum, Biederman, Hirshfeld, Bolduc, \& Chaloff, 1991), depression (Muris, Meesters, \& Spinder, 2003; Muris, Merckelbach, Schmidt, Gadet, \& Bogie, 2001), and obsessive-compulsive disorder (Coles, Schofield, \& Pietrefesa, 2006), and BI could mark an increased predisposition for comorbidity of depressive and anxious disorders (Rosenbaum et al., 2000). In a recent meta-analysis, Clauss and Blackford (2012) found a greater than sevenfold increase in the risk for developing social anxiety disorder among individuals high in BI. This increased vulnerability to social anxiety has been observed across studies using different methods, including retrospective studies in which participants recalled their own childhood levels of BI (e.g., Gladstone et al., 2005; Hayward, Killen, Kraemer, \& Taylor, 1998; Rotge et al., 2011) as well as longitudinal studies collecting observational (e.g., Biederman et al., 2001; HirshfeldBecker et al., 2007) and parent reported (e.g., Muris, van Brakel, Arntz, \& Schouten, 2011) BI.

However, the influence of BI on vulnerability may vary as a function of its continuity over time; in particular, relative to children who exhibit high BI at a single time point, longitudinal studies show that youth with persistently high BI show a robust increase in vulnerability to anxiety disorders 
(e.g., Hirshfeld, et al., 1992; Vreeke, Muris, Mayer, Huijding, \& Rapee, 2013). For example, Chronis-Tuscano et al. (2009) observed that maternally reported, persistently high BI across infancy and early childhood was associated with an almost four times increased risk for a diagnosis of social anxiety disorder in adolescence. In addition, in a longitudinal study of 238 children followed from birth to ninth grade, Essex, Klein, Slattery, Goldsmith, and Kalin (2010) found that persistently high BI, assessed using self- and informant reports (i.e., mothers', teachers', and children's reports), was related to increased vulnerability to social anxiety disorder by adolescence. Thus, persistently elevated BI appears to confer especially heightened vulnerability to negative outcomes, suggesting that identifying factors that predict its continuity should be an important goal for developmental psychopathologists.

\section{Continuity of BI}

Temperament and personality traits, including BI, are conceptualized as "endogenous basic tendencies" (McCrae et al., 2000, p. 175) that exhibit both continuity and change over time. Consistent with this, moderate albeit variable estimates of the continuity of BI are reported (e.g., Essex et al., 2010; Johnson et al., 2016; Kagan, Reznick, \& Snidman, 1988; Kerr, Lambert, Stattin, \& Klackenberg-Larsson, 2014; Natsuaki et al., 2013; Rubin, Burgess, \& Hastings, 2002; Scarpa, Raine, Venables, \& Mednick, 1995). These estimates vary due to an array of factors, such as how BI was assessed (e.g., laboratory vs. parent report), the consistency with which BI was operationalized at different assessments, the time frame used for follow-up(s), and whether children were recruited based on extreme BI scores, among other factors. Initially, Kagan and Moss (1962) reported high persistence of fearfulness in toddlers they followed through adulthood; in subsequent studies, Kagan, Reznick, Clarke, Snidman, and Garcia-Coll (1984) and Kagan, Reznick, Snidman, Gibbons, and Johnson (1988) reported moderate continuity of BI in children selected for extreme BI. For example, Kagan, Reznick, and Snidman (1988) reported significant correlations between observed BI between 14 and 20 months $(r=.52)$ and 14 and 32 months $(r=.44)$ in 100 children; however, BI at ages 14 and 20 months was unrelated to age 4 BI. Similarly, Gest (1997) found that interviewer-rated BI showed strong continuity in both childhood (median $r=.55$ ) and early adulthood (median $r=.59$ ). In contrast, Scarpa et al. (1995) found much lower continuity of BI in Mauritian children assessed for BI at the ages of 3, 8, and 11 years ( $r s=.10-.21)$, using observational measures and informant reports. Overall, this work indicates both continuity and change in BI (e.g., Degnan \& Fox, 2007; Kagan, 1997).

Given that persistently elevated BI is implicated in vulnerability, a greater understanding of which factors moderate the relationship between early and later BI could facilitate targeted, and thus cost-effective, prevention and intervention strategies. Studies speaking to this question have implicated an array of factors in the continuity of BI, reviewed as follows. Only some of this work has used longitudinal methods; nevertheless, because factors associated with BI at one time point may also influence its continuity, studies using both cross-sectional and longitudinal designs are reviewed here. Work examining constructs related to BI (e.g., shyness and social reticence), as well as BI's predictive validity for conceptually related constructs, will also be discussed.

\section{Caregiver factors, BI, and its continuity}

Parenting. Associations between parenting and children's BI have been extensively studied. Linkages between BI and early care likely develop through multiple, complex pathways, some of which may involve gene-environment correlation such that the same genetic variants that predispose to maladaptive parenting also confer heightened BI to children; here, our goal is to describe the literature from an agnostic standpoint with regard to the origins of parenting and the mechanisms behind parenting-BI associations.

Early care appears to be an important consolidating influence (e.g., Hane, Cheah, Rubin, \& Fox, 2008; Rubin et al., 2002). For example, Rubin et al. (2002) found that observationally assessed maternal intrusive control and derisive comments moderated the relationship between 2-year-olds' BI and social reticence at age 4 , such that when mothers exhibited intrusive control and/or derisive comments, children who were high in $\mathrm{BI}$ at age 2 were high in social reticence at age 4. In another study, Hane et al. (2008) found that observed maternal hostility and negative control moderated the relationship between children's reticence at age 4 and social withdrawal at age 7; children who were high in reticence at age 4 and who were exposed to high maternal negativity exhibited high levels of social withdrawal at age 7. Rubin, Hastings, Stewart, Henderson, and Chen (1997), moreover, found that toddlers who were consistently inhibited across nonsocial, adult-social, and peer-social contexts had mothers who were high in observed oversolicitousness, a parenting style characterized by unresponsive yet physically affectionate care.

However, less work has tested the moderating role of parental overinvolvement (i.e., parental care that is overly involved, excessively controlling, or protective) in consolidating children's BI over time, despite the intuitive appeal of such models. Multiple mechanisms could drive the influence of overinvolvement on BI continuity. Given that BI is characterized by fearfulness and reticence when confronted with novelty, parenting that facilitates exposure to, rather than protects children from, unfamiliar stimuli may serve to reduce BI over time. Thus, lower levels of parental overinvolvement might increase children's exposure to novelty, thereby enhancing the occasions children have to learn coping strategies for confronting novel, anxiety-provoking situations, consequently leading to lower child BI (e.g., Muris et al., 2011). Such an explanation would be consistent with behavioral models of anxiety that focus on the role of exposure in treating anxiety (e.g., Abramowitz, Deacon, \& Whiteside, 2010). 
Similarly, it would also be consistent with the principle of "steeling," which proposes that mild stress exposure promotes resilience (e.g., Liu, 2015; Rutter, 2012). This collective literature indicates that conquering mild stressors may facilitate new learning and coping skills, as well as a sense of psychological mastery, thereby leading to resilience and use of adaptive strategies when confronted with consequent stress (e.g., Wu et al., 2013); the absence of such mild stressors, as in the case of high levels of parental overinvolvement, may therefore contribute to the persistence of high BI over time.

Although aspects of overinvolved parenting and related constructs have been associated with both child anxiety and BI continuity, most of the relevant literature has focused on the mediating role of related parenting behaviors. For example, Kiel and Buss (2012) found that observed overprotective parenting (defined as excessive parental comfort and affection, as well as parenting that shelters children from stress yet constrains children's autonomy) mediated the relationship between observed fearful temperament at age 2 and maternally reported shyness/inhibition at age 3. Furthermore, parental overcontrol, a construct that shares features with overprotective parenting (i.e., inappropriate and excessively "protective, directive, and controlling behaviors," LewisMorrarty et al., 2012, p. 1365), may increase the vulnerability to anxiety associated with BI. Lewis-Morrarty et al. (2012) investigated the relationship between persistently elevated $\mathrm{BI}$, parental overcontrol, and social anxiety, finding that persistently elevated BI in childhood was significantly associated with greater social anxiety in adolescence only when mothers were also high in overcontrol, suggesting that heightened BI over time may mark anxiety vulnerability most clearly in the context of overprotective parenting. However, given the potentially vast and cost-effective implications for parenting interventions, extension of this research is imperative. Because the majority of parenting styles previously implicated in BI continuity involve aspects of overinvolvement, such care may serve to consolidate BI in early childhood. Thus, longitudinal research specifically examining the role of overinvolvement on the continuity of BI is needed.

Parent anxiety disorder. Parent anxiety may influence the continuity of child BI through various mechanisms. Crosssectional associations between parental internalizing disorders (i.e., anxiety and depression) and children's BI have been reported; for example, Rosenbaum et al. (2000) observed that young children (between the ages of 2 and 6) of parents with both panic disorder and major depression displayed elevated rates of BI. In addition, Aktar, Majdandžić, de Vente, and Bögels (2013) found links between infant BI, expressed parental anxiety, and infant avoidance, such that expressed parental anxiety was related to infants' avoidant behaviors only when infants showed moderate to high levels of BI. However, longitudinal research on the influence of parental anxiety disorder on the continuity of children's BI is lacking.

In addition, parental internalizing disorder is associated with distinct, potentially maladaptive parenting styles (e.g.,
Degnan \& Fox, 2007). Mothers with diagnosed anxiety, for example, have been shown to grant less autonomy and engage in catastrophizing when parenting (Moore, Whaley, \& Sigman, 2004; Whaley, Pinto, \& Sigman, 1999; WoodruffBorden, Morrow, Bourland, \& Cambron, 2002); these highrisk parenting behaviors may subsequently influence the continuity of child BI. Given the ties between maternal anxiety and parenting styles implicated in children's BI (i.e., parental overinvolvement), studies must account for both parental anxiety and parental overinvolvement to determine the unique effects of each, if any, on the persistence of child BI; however, very few studies have included both putative influences in the same model.

\section{Child factors influencing BI and its continuity}

Genes. Specific genetic variants have been implicated in BI or related behaviors (e.g., Garcia et al., 2013; Lamb et al., 2010; Rogers, Shelton, Shelledy, Garcia, \& Kalin, 2008; Rubin et al., 2013), particularly within high-risk contexts (e.g., poor parenting; Burkhouse, Gibb, Coles, Knopik, \& McGeary, 2011). One such gene is the serotonin transporter (5-HTT) gene, particularly the linked polymorphic region variant (5-HTTLPR; e.g., Fox, Henderson, Marshall, Nichols, \& Ghera, 2005; Lanzenberger et al., 2007; Ohara, Nagai, Suzuki, Ochiai, \& Ohara, 1998; Schinka, Busch, \& RobichauxKeene, 2004). For example, Fox, Nichols, et al. (2005) found that children with a 5-HTT short allele exhibited greater BI in the context of low social support. The association between 5-HTTLPR and amygdala responding may be a neural mechanism that explains the polymorphism's influence on BI, given a recent meta-analysis finding associations between the short 5-HTTLPR allele and heightened amygdala activity (Murphy et al., 2013). Individuals with elevated BI in infancy have been found to display heightened amygdala responses to novelty in adulthood (Schwartz, Wright, Shin, Kagan, \& Rauch, 2003).

The 5-HTTLPR polymorphism has recently been invoked as a marker of differential susceptibility or biological plasticity to context (Belsky \& Pluess, 2012, 2013; Belsky et al., 2009; Pluess \& Belsky, 2009). These concepts posit that biological or other processes confer heightened responsivity to experience, such that those with such characteristics exhibit especially negative outcomes in the presence of adversity and especially positive outcomes in the presence of positive, supportive contexts (e.g., Belsky \& Pluess, 2009, 2013; Boyce \& Ellis, 2005). In particular, 5-HTTLPR may be a marker of such plasticity because it has been found to moderate the influence of current life events on neuroticism; when compared to individuals with two copies of the 5-HTTLPR long allele, individuals with two copies of the 5-HTTLPR short allele exhibited greater neuroticism in the presence of more negative life events but exhibited less neuroticism in the presence of more positive life events (Pluess, Belsky, Way, \& Taylor, 2010). Other studies have found genetic susceptibility to family support, such that youth with the short allele tended to 
have greater depressive symptoms in the presence of poor family support and tended to have the fewest depressive symptoms in the presence of high family support (e.g., Dalton, Hammen, Najman, \& Brennan, 2014; Li, Berk, \& Lee, 2013) relative to those without this allele. In addition, the 5-HTTLPR short allele has been associated with differential susceptibility to depression in stressful contexts. Specifically, one study found that children with the short allele displayed increased depressive symptoms when exposed to high stress and fewer depressive symptoms when exposed to low stress, compared to children without a short allele. In this study, differential susceptibility was only found for children who showed low levels of emotion regulation and also had a short allele, suggesting the complexity of Gene $\times$ Environment $(\mathrm{G} \times \mathrm{E})$ interactions (Ford, Mauss, Troy, Smolen, \& Hankin, 2014).

Given the emerging literature implicating 5-HTTLPR in differential susceptibility (e.g., Dalton et al., 2014), and the associations between 5-HTTLPR and BI (e.g., Burkhouse et al., 2011), research investigating the potential role of 5-HTTLPR in moderating the continuity of BI over time may be relevant in mitigating vulnerability to internalizing disorders. More specifically, the 5-HTTLPR short allele may leave children more susceptible to both positive and negative contexts. To the extent that such children encounter an array of contextual influences during childhood, some of which serve to increase BI and some of which decrease BI, these children may exhibit less continuity of BI over time compared to children without this allele.

\section{Objectives of Current Study}

The current study investigated moderators of the continuity of BI in early childhood, building on extant work by examining a broader range of putatively relevant biological and contextual factors, using a multimethod, longitudinal approach and a community sample of a larger size than most previously studied. Based on previous research (e.g., Johnson et al., 2016; Kiel \& Buss, 2012; Lewis-Morrarty et al., 2012), we predicted that parental overinvolvement would moderate the relationship between BI at baseline and follow-up, such that overinvolvement at baseline would increase the continuity of BI. In an extension of the cross-sectional research on parental internalizing disorder and $\mathrm{BI}$, we also aimed to longitudinally investigate the potential moderating role of parental anxiety on the continuity of BI, predicting that parental anxiety would interact with child BI to increase the continuity of BI over time. Finally, we planned to test the influence of a proposed "plasticity gene" on BI in young children, predicting that the short variant of the 5-HTTLPR would be associated with lower continuity of BI between the ages of 3 and 5 years, due to its putative role in heightening children's responsivity to a broad array of influences likely to both increase and decrease BI.

Due to the difficulties associated with assessing temperament and related constructs in infancy (e.g., Hubert, Wachs, Peters-Martin, \& Gandour, 1982) and considering that early childhood is a developmental period during which there is support for increased continuity of temperament as well as plasticity (e.g., Caspi et al., 2003; Van den Akker, Deković, Prinzie, \& Asscher, 2010), we initially assessed children at age 3 and then again at age 5. Moreover, our study's emphasis on parental factors also led us to concentrate on early childhood, because parents are the main source of children's socialization during early childhood and have a crucial influence on children's development during this age range (e.g., Root \& Stifter, 2010) and long-term (e.g., Essex et al., 2010). In addition, we relied on laboratory measures to assess $\mathrm{BI}$, which are viewed as the "gold standard" approach (Kagan, 2003). Furthermore, given that much of the current BI literature has focused on discrete groups of children with extreme levels of BI (e.g., Kagan, Reznick, Snidman, Gibbons, \& Johnson, 1988), which potentially inflates estimates of BI continuity, the present study used continuous measures of BI, looking at children across the range of BI scores.

\section{Method}

Data for this study were collected in two waves. The first wave was collected over 2 years and comprised a 2-hr laboratory visit (during which child DNA, child temperament data, and observed parenting data were collected) and a 2.5-hr home visit carried out within 2 weeks of the laboratory visit (during which additional observed parenting data were collected). The second wave was initiated roughly 30 months after the first laboratory visit and comprised a 2-hr laboratory visit (during which child temperament and observed parenting data were collected) and a telephone or face-to-face interview (during which the lifetime psychiatric history of biological caregivers was assessed).

\section{Baseline assessment}

Participants. Participants were an unselected community sample of 409 families from southwestern Ontario. Families were recruited through a university's developmental research participant pool and through advertisements placed in local daycares, preschools, recreational facilities, and on websites. A screening procedure administered by trained study personnel at the recruitment phase was used to exclude children with significant medical or psychological impairments. The Peabody Picture Vocabulary Test (PPVT; Dunn \& Dunn, 1997) was administered to children to screen for significant cognitive impairment and English proficiency; participants scored within the average range $(M=111.94, S D=14.32)$. Written consent for the child was acquired from the child's primary caregiver; written consent from parents for their own participation was also attained. Monetary compensation was provided, the total amount of which varied depending on the aspect of the study in which participants were involved (e.g., participants received $\$ 100$ CAD for participation in the laboratory visit).

Children (201 boys; $49.1 \%$ ) were a mean age of 3.43 years $(S D=0.30)$ and most had mother as their primary caregiver 
$(N=380 ; 93.0 \%)$. The mean age of mothers was 33.25 years $(S D=4.62)$, and the mean age of fathers was 35.01 years $(S D=4.89)$. Of the families for whom we have the following demographic data, approximately one-quarter of children spent no time in care outside of the house (e.g., daycare or preschool; $N=105 ; 26.0 \%)$. Most mothers $(N=259$; $71.6 \%)$ and fathers $(N=350 ; 94.0 \%)$ worked outside of the home. Most mothers $(N=366 ; 93.7 \%)$ and fathers $(N=316 ; 82.0 \%)$ had at least some postsecondary education.

Of the families for whom we had data on ethnicity $(N=$ $405 ; 99.0 \%)$, 91.6\% identified themselves as Caucasian $(N=371), 1.5 \%$ identified as Asian $(N=6)$, and $6.9 \%$ identified as other race $(N=28)$. The majority of parents were married $(N=330 ; 81.7 \%)$ or living together $(N=24 ; 5.9 \%) ; 1.5 \%$ of participants did not provide this information $(N=6)$. Almost all of the participating children for whom we have data lived with their biological mothers $(N=398 ; 98.3 \%)$ and biological fathers $(N=354 ; 87.4 \%)$. Approximately half of the families reported a family income between $\$ 40,000$ and $\$ 100,000$ CAD $(N=207 ; 50.4 \%), 29.8 \%$ reported a family income of over $\$ 100,000 \mathrm{CAD}(N=122), 10.7 \%$ reported an income between $\$ 20,000$ and $\$ 40,000 \mathrm{CAD}(N=44), 3.9 \%$ reported an income of less than $\$ 20,000 \mathrm{CAD}(N=16)$, and 5.1\% $(N=$ 21) did not report a family income.

Laboratory assessment of temperament and parenting. Children participated in 12 standardized laboratory tasks taken from the Laboratory Temperament Assessment Battery (Lab-TAB; Goldsmith, Reilly, Lemery, Longley, \& Prescott, 1995) with a female experimenter. Tasks were designed to elicit a wide array of temperamental characteristics and were videotaped for coding purposes. Carryover effects were minimized by ensuring that no tasks meant to elicit comparable affective reactions occurred successively; children were also given a short opportunity to play in between each task to return to a baseline state. The complete assessment spanned a total of 1.5 to $2 \mathrm{hr}$.

Of the 12 Lab-TAB tasks, BI was coded in three tasks (risk room, stranger approach, and jumping spider), which were selected based on previous research using similar tasks to assess behaviors relevant to the trait of BI. Such procedures are consistent with past research using observational measures of temperament (e.g., Durbin, Klein, Hayden, Buckley, \& Moerk, 2005; Mackrell et al., 2014; Olino, Klein, Dyson, Rose, \& Durbin, 2010), which suggest BI is a specific response to novel situations (e.g., Laptook, et al., 2008; Laptook, Klein, Olino, Dyson, \& Carlson, 2010). A parent was present in the main experimental area with his/her child for all episodes except stranger approach and two other episodes not used in the present study; he or she was instructed to work on questionnaires at a desk in the back corner of the room while avoiding interaction with the child. Parenting was coded in one task. A description of the three BI episodes and the parenting episode is provided below.

Risk room. The child and experimenter entered a room containing novel and ambiguous stimuli, including a small staircase, a mattress, a balance beam, a Halloween mask, a cloth tunnel, and a large, black cardboard box. The experimenter left for 5 min after instructing the child to play with the stimuli "however you like." When the experimenter returned, she asked the child to interact with each stimulus in the room.

Puzzle with parent (teaching task). Based on the Teaching Tasks battery (Egeland et al., 1995), the child and parent were seated at a table in the center of the experimental room and given a difficult block puzzle to work on together for $5 \mathrm{~min}$ while the experimenter left them alone. Child and parent collaborated on the puzzle, which had six different solutions, until the experimenter returned. To enhance motivation to complete the puzzle, the dyad was told to place the pictures of their completed puzzles on one corner of their table so they could show the experimenter how many they were able to solve by the end of the episode. This task was coded for parenting behavior (as described subsequently).

Stranger approach. The child was left alone in the experimental area under the premise that the experimenter needed to get a toy for further play. While the child was alone, an unfamiliar male research assistant entered the room and spoke to the child while slowly moving closer, following a standardized script and timed intervals. After asking the child four standardized questions, the stranger left and the main experimenter returned. The same stranger then returned, greeted the experimenter and child, and was introduced to the child as the experimenter's friend.

Jumping spider. The child and experimenter were seated at a table in the center of the room when a research assistant brought in a terrarium with a fuzzy, fake, black spider and placed it on the table. The experimenter showed the spider to the child and asked the child to touch the spider; when the child's hand was close to the spider, the experimenter manipulated the spider using an attached wire, making it appear to jump. This was repeated for a total of four trials, with the experimenter coaxing the child to touch the spider each time. At the end of the fourth trial, the experimenter showed the child that the spider was a toy.

BI coding. Videorecordings of the laboratory tasks were coded by trained graduate and undergraduate raters. Raters were trained to an intraclass correlation of 0.80 with a master coder. Once this standard was reached, periodic reliability checks were conducted on $15 \%-20 \%$ of all participants. Coders periodically met as a group to review recordings and prevent observer drift.

BI microcoding. Episodes were divided into 20- to 30-s epochs, using a system based on Goldsmith et al. (1995). In each epoch, fearful affect was coded such that the maximum intensity display was rated on a 3-point scale. As described in the next section, specific behaviors were coded in each indi- 
vidual epoch to evaluate the presence and intensity of conventional BI behavioral responses. The peak intensity of each behavior was coded for all epochs.

Risk room was divided into two phases for coding purposes. The first phase, which was divided into $30-$ s epochs, began when the child entered the room and ended when the experimenter returned. Latencies to touch each specific object were recorded, as well as the latency to the child's first fear response and to the child's first verbalization. In each epoch, bodily fear, tentative play, time spent playing, references to parent (i.e., child looks to parent), proximity to parent, fearful or wary questions or comments, and amount of time talking were all coded. The second phase of this episode began when the experimenter returned to the room and ended when the child and experimenter exited the room. In this phase, latencies to comply with the experimenter's requests were recorded. This phase was divided into 20-s epochs for microcoding. All the same behaviors were coded as in the first phase, with the exception of time spent playing and amount of time talking. In addition, noncompliance and references experimenter (i.e., child looks to experimenter) were coded.

In stranger approach, bodily fear and vocal fear were coded during each epoch using codes highly similar to those used to code risk room. In addition to these behaviors, stilling/freezing was coded as the duration, in seconds, that a child exhibited a marked decrease in activity that exceeded two seconds and involved little or no movement. Approach, avoidance, gaze aversion, and verbal/nonverbal interaction were also coded; however, they were coded only for epochs in which the stranger was present. The latency from the time the experimenter said she would leave the room to the child's first fear response was also recorded, as was the latency from the time the stranger entered the room to the child's first vocalization.

Jumping spider was divided into four trials for coding purposes; each trial began when the experimenter told the child to "go ahead and pet the spider." Latency to the first definite fear response was coded. In each trial, intensity of fear expression, intensity of bodily fear, intensity of vocal distress, intensity of bodily fear, approach, withdrawal, gaze aversion, and startle were coded. At the end of the episode, the presence or absence of play with spider was coded based on the child's play with the spider when given the opportunity to do so after the last trial. Verbalizations were also coded as present if the child vocalized during the episode.

Reliability for each task was high (risk room intraclass correlation $[\mathrm{ICC}]=0.92$, stranger approach $\mathrm{ICC}=0.87$, jumping spider ICC $=0.91$ ). Item analysis was used to create a BI scale, after standardizing and reverse-coding items as necessary. The final BI scale consisted of an average of $z$-scored codes $(\alpha=0.79, N=39$; ICC $=0.71, N=32)$ from risk room, stranger approach, and jumping spider.

Parenting coding. Video recordings of the laboratory visits (i.e., puzzle with parent) were coded by trained undergraduate and graduate raters who were trained in the same manner as the BI coders. Parenting variables were coded such that a global rating for each variable was given based on the parent-child interactions throughout the entire episode. Ratings scales were developed from the Teaching Tasks coding manual (Weinfield, Egeland, \& Ogawa, 1998) and Qualitative Ratings for Parent-Child Interactions (Cox \& Crnic, 2003). Seven scales concentrated on parent behavior, eight scales concentrated on child behavior, and two scales were more dyadic. For purposes of the current study, the parent intrusiveness scale was used. Parent intrusiveness was coded on a 7 point scale ranging from 1 (none) to 7 (very high). Reliability for the teaching task was high $(\mathrm{ICC}=0.90 ; N=61)$.

Genetic data. At the initial laboratory visit, buccal cell samples were collected from all 409 participants by softly rubbing the inside of the child's cheek with a cotton swab (Epicentre, Madison, WI), and was extracted by Qiagen DNA MicroKit ${ }^{\circledR}$ (Mississauga, ON, Canada). DNA was extracted following manufacturer's protocols. All children were genotyped for the serotonin transporter promoter (5-HTTLPR short/long) gene variants using allele-specific TaqMan polymerase chain reaction (Sheikh, Hayden, Kryski, Smith, \& Singh, 2010). For 5-HTTLPR, allele frequencies were as follows: long/ long $=127(31 \%)$, short/long $=193(48 \%)$, and short/short $=85(21 \%)$. This genotype distribution is consistent with Hardy-Weinberg equilibrium, $\chi^{2}(1)=0.54, p=.46$. Given the previous literature on plasticity (e.g., Dalton et al., 2014; Li et al., 2013; Pluess et al., 2010), children with a copy of the short allele were considered to possess the 5-HTTLPR plasticity allele.

Home assessment of parenting. Observed parenting data was also collected during a home visit that occurred within 2 weeks of the laboratory visit. Two semistructured parenting tasks were conducted during this home visit, called the three bag and prohibition tasks.

Three bag task. This task was established from a task developed by the National Institute of Child Health and Human Development (1997), modified by Ipsa et al. (2004). The primary caregiver and his or her child were directed to play together with three bags of toys. The first bag held a book, the second bag held a set of toy kitchen items, and the third bag held a farmhouse play set. The pair was instructed to play with the toys in order and to put away one set of toys before proceeding to the next set. This free play paradigm continued for approximately $10 \mathrm{~min}$.

Prohibition task. This task was intended to elicit negative parenting behaviors. The primary caregiver and the child were given two boxes of toys, the first of which contained toys that would be fun or exciting for children in this age group (e.g., a toy electronic guitar), and the second of which contained unexciting and age-inappropriate toys that were missing pieces or batteries (e.g., a plastic cone and pieces for Mr. Potato head without the head). To begin with, the primary caregiver was instructed to prevent his or her child from 
playing with the appealing toys, thus forcing the caregiver to engage the child in play with the unappealing toys. After 3 min, the primary caregiver was told that he or she could allow the child to play with the toys in either box, and after 6 min of play, the caregiver was directed to have the child put away the toys. The child then received $5 \mathrm{~min}$ to tidy up. The experimenter provided the primary caregiver with printed instruction cards to increase the child's perception that these orders were coming from the caregiver instead of the experimenter.

Parenting coding. Video recordings of the home parenting tasks were again coded by trained graduate and undergraduate raters using a coding system virtually identical to that used for coding the laboratory parenting task. The parent intrusiveness scale was used for purposes of this study. Reliability for both parenting tasks was high (three bag ICC $=0.86, N=61$; prohibition ICC $=0.87, N=61$ ). The final parental overinvolvement variable consisted of an average of $z$-scored intrusiveness scores for three bag, prohibition, and puzzle with parents; in cases where participants did not have intrusiveness scores for all three tasks, an average of the available intrusiveness scores were used to form the final overinvolvement score.

\section{Follow-up assessment}

Participants. Follow-up participants were 371 of the initial 409 families, an attrition rate of 9.5\%. Participants who dropped out of the study were not significantly different from those who completed the follow-up on most study variables. However, children who did not participate in the follow-up assessment had significantly lower baseline PPVT scores compared to children who participated in both assessments $(M=107.68$ vs. 112.44$), t(397)=1.97 p=.049$, although both were in the normal range of scores. The followup visit occurred an average of 29.63 months $(S D=1.55)$ following the baseline laboratory assessment, when children were an average of 5.93 years old $(S D=0.31)$.

Laboratory assessment of temperament. Children participated in 12 standardized laboratory tasks taken from an adapted version of the Lab-TAB (Goldsmith et al., 1995), which were similar to the initial laboratory tasks but designed to be age-appropriate for somewhat older children. Similar to the baseline assessment, BI was assessed in three tasks: exploring new objects, stranger approach, and object fear; because these were the only episodes used in the current study, the remainder of the tasks are not described further here.

Exploring new objects. The child and experimenter entered a room containing various novel and ambiguous stimuli, which included a tunnel, a remote-controlled spider, a skull and cloth, a box with a toy heart inside, and a box with "worms" inside. The experimenter left for a total time of 5 min after giving the child permission to play with the objects in the room. When the experimenter returned, she asked the child to interact with each stimulus in the room.
Stranger approach. The child was left alone in the experimental area with a toy. While the child was alone, an unfamiliar male research assistant entered the room. Following a standardized script and timed intervals, he asked the child friendly questions and asked to play with the toy together.

Object fear. The experimenter instructed the child to investigate "something scary" in a pet carrier, leaving the child alone in the room. After $1 \mathrm{~min}$, the experimenter returned and asked the child about the item in the animal carrier. If the child had not explored the carrier, the experimenter asked the child to look and to put his or her hands into the carrier with the experimenter present. The episode concluded with the child discovering or being shown that the carrier contained a stuffed animal hidden by shredded newspaper.

BI coding. At the age 5 follow-up, affective and behavioral microcoding procedures were very similar to those used for the initial age 3 baseline tasks. Videorecordings of the follow-up laboratory visits were again coded by trained undergraduate and graduate raters; these raters were trained in the same manner as those who coded the laboratory tasks from the initial baseline laboratory visit. Interrater reliability for each BI task was high (exploring new objects $\mathrm{ICC}=86.3$, $N=55$; stranger approach ICC $=85.7, N=47$; object fear $\mathrm{ICC}=77.8, N=52$ ). The final BI scale consisted of an average of $z$-scored codes $(\alpha=0.88, N=67 ; \mathrm{ICC}=0.98, N=24)$ from exploring new objects, stranger approach, and object fear.

Diagnostic interviews with parents. The Structured Clinical Interview for DSM-IV (SCID; First, Gibbon, Spitzer, \& Williams, 1996) was used to assess parent anxiety disorder history. The SCID is one of the most extensively used diagnostic interviews, and has demonstrated interrater reliability and procedural validity (First et al., 1996). PhD candidates in the clinical psychology program administered the SCID after training by a PhD-level psychologist, the principal investigator on the larger study. The interviewers were not involved in data collection and did not have access to data on the children. In cases where a second biological parent was unavailable to complete the SCID, a family history interview was conducted with the primary biological caregiver when possible (Andreasen, Endicott, Spitzer, \& Winokur, 1977); data for 11 biological fathers were gathered through family history interviews while all mothers completed the SCID.

For purposes of the current study, a composite variable for maternal anxiety was computed based on all maternal anxiety disorder variables covered by the SCID; maternal history of any anxiety disorder was coded as 1 and maternal history of no anxiety disorders was coded as 0 . A composite variable for paternal anxiety was computed in the same way. At baseline, 110 children $(27 \% ; 21 \%$ of mothers and $8 \%$ of fathers) had at least one parent with a lifetime history of any anxiety disorder, a rate comparable to that reported in major epidemiological studies. Given the risk conferred for child anxiety when either parent has a history of anxiety (e.g., Franić, Mid- 
deldorp, Dolan, Ligthart, \& Boomsma, 2010; Garcia et al., 2013), a final parental anxiety variable was computed to capture this familial risk; in the case where either a mother or a father had a history of any anxiety disorder, parental anxiety was coded as 1 and when neither mother nor father had such a history, as 0. Interrater reliability for the SCID was calculated based on 33 audiotaped interviews (21 mothers and 12 fathers) and was high (lifetime anxiety disorder, $\kappa=1.00$ ).

\section{Results}

Means, standard deviations, and bivariate correlations between demographic and other study variables are presented in Table 1. Age 3 and age 6 BI were significantly positively correlated, albeit modestly so; while this correlation was fairly similar to laboratory-based studies of BI found across comparable follow-up intervals (e.g., Broberg, Lamb, \& Hwang, 1990; Scarpa et al., 1995), it was smaller than associations reported in other studies, especially those involving children selected for extreme BI scores (e.g., Kagan et al., 1984; Kagan, Reznick, \& Snidman, 1988). Age 3 and age 6 BI were significantly and positively correlated with child sex, such that girls exhibited higher BI than boys; this association is consistent with some past work (e.g., Essex et al., 2010; Hane et al., 2008). BI at both time points was significantly and negatively correlated with child age at baseline, albeit very modestly so. Age 3 BI showed a small, significant positive correlation with 5-HTTLPR, such that children with at least one copy of the short allele exhibited higher age $3 \mathrm{BI}$.

In addition, parental overinvolvement at baseline was significantly and negatively correlated with child sex and child age at baseline; parents displayed more overinvolvement with younger children, and with boys. Overinvolvement showed a small, significant negative correlation with PPVT scores, such that higher overinvolvement was associated with lower PPVT scores. Moreover, family income showed a small, significant positive correlation with children's PPVT scores. Family income also showed small, albeit significant, negative correlations with age $3 \mathrm{BI}$ and overinvolvement. There were no significant correlations between parental anxiety and any relevant study variables.

Multiple regression was used to investigate whether putative influences on the continuity of child BI interacted with age $3 \mathrm{BI}$ to predict age $5 \mathrm{BI}$, following standard procedures for testing interactions in multiple regression (Aiken \& West, 1991). Prior to running the regression analyses, continuous variables were standardized and dichotomous variables were dummy-coded. Given research showing sex differences in BI (e.g., Doey, Coplan, \& Kingsbury, 2014; Fox, Henderson, et al., 2005) and the significant correlations between child sex and age $3 \mathrm{BI}$, age $5 \mathrm{BI}$, and parental overinvolvement in this data, child sex was treated as a covariate in all models. Because child age at baseline was also significantly correlated with all temperament variables and parental overinvolvement, we initially included it as a covariate in all models; however, because there were no significant main effects of child age and including it as a covariate did not change our findings, it was dropped from final models. Partial correlations $\left(r_{\mathrm{p}}\right)$ are provided as bounded measures of effect size. Given our examination of the 5-HTTLPR, we ran models excluding all non-Caucasian participants to address population stratification. However, results were virtually identical with the inclusion of non-Caucasian participants in models; thus, models including all participants are presented here.

To make final models more parsimonious, nonsignificant interaction terms in preliminary model tests were dropped. Tests of simple slopes and regions of significance were used to understand significant interactions. To test regions of significance, Hayes and Matthes' (2009) guidelines for the Johnson-Neyman technique (Johnson \& Fay, 1950)

Table 1. Correlations between study variables

\begin{tabular}{|c|c|c|c|c|c|c|c|c|c|c|}
\hline & 1 & 2 & 3 & 4 & 5 & 6 & 7 & 8 & 9 & 10 \\
\hline 1. Age $3 \mathrm{BI}$ & - & & & & & & & & & \\
\hline 2. Age $5 \mathrm{BI}$ & $.28 * *$ & - & & & & & & & & \\
\hline 3. 5-HTTLPR & $.11 *$ & -.01 & - & & & & & & & \\
\hline 4. Age 3 paren. overinvolv. & -.05 & -.03 & -.02 & - & & & & & & \\
\hline 5. Parental AD & .05 & .05 & .06 & -.03 & - & & & & & \\
\hline 6. Family income & .05 & $-.10 *$ & .04 & $-.17 * *$ & -.07 & - & & & & \\
\hline 7. Child sex & $.15 * *$ & $.18 * *$ & .07 & $-.11 *$ & -.01 & -.02 & - & & & \\
\hline 8. Child age & $-.17 * *$ & $-.10 *$ & -.06 & $-.11 *$ & -.03 & .06 & .06 & - & & \\
\hline 9. Child race & -.06 & -.09 & -.03 & -.09 & -.04 & .07 & -.06 & -.06 & - & \\
\hline 10. PPVT score & -.05 & -.01 & .04 & $-.28 * *$ & .01 & $.11^{*}$ & .07 & .05 & -.02 & - \\
\hline$N$ & 409 & 394 & 405 & 409 & 409 & 389 & 409 & 409 & 409 & 399 \\
\hline Mean or $\%$ & 0.0036 & 0.0068 & $69 \%$ & 2.79 & $27 \%$ & 3.73 & $51 \%$ & 3.43 & $92 \%$ & 112.00 \\
\hline$S D$ & 13.00 & 0.44 & - & 0.46 & - & 0.94 & - & 0.44 & - & 0.50 \\
\hline
\end{tabular}

Note: BI, Behavioral inhibition; 5-HTTLPR, serotonin transporter linked polymorphic region gene; AD, anxiety disorder; PPVT, Peabody Picture Vocabulary Test. 5-HTTLPR reported as percentage with a short allele; child sex reported as percentage girls; child age reported in years at age 3 assessment; child race reported as percentage Caucasian; parental $\mathrm{AD}$ reported as percentage of children with a parent with a lifetime $\mathrm{AD}$; family income: $1=<\$ 20,000$, $2=\$ 20,000-\$ 40,000,3=\$ 40,001-\$ 70,000,4=\$ 70,001-\$ 100,000,5=>\$ 100,000$

$* p<.05 . * * p<.01$. 
Table 2. Children's age 3 BI and child and parent factors as predictors of children's age 5 BI

\begin{tabular}{|c|c|c|c|c|c|c|c|c|}
\hline & \multicolumn{4}{|c|}{ Overall Model } & \multicolumn{4}{|c|}{ Change Statistic } \\
\hline & $d f$ & $R^{2}$ & $F$ & Cohen $f^{2}$ & $d f$ & $\Delta R^{2}$ & $\Delta F$ & $\beta$ \\
\hline Step 1 & 5,384 & .10 & $8.41 * * *$ & 0.11 & & & & \\
\hline Age 3 BI & & & & & & & & $0.26 * * *$ \\
\hline 5-HTTLPR & & & & & & & & -0.05 \\
\hline Overinvolvement & & & & & & & & 0.001 \\
\hline Parental anxiety & & & & & & & & 0.04 \\
\hline Child sex & & & & & & & & $0.14 * *$ \\
\hline Step 2 & 6,383 & .11 & $8.20 * * *$ & 0.12 & 1,383 & .02 & $6.56 *$ & \\
\hline Age 3 BI & & & & & & & & $0.51 * * *$ \\
\hline 5-HTTLPR & & & & & & & & -0.06 \\
\hline Overinvolvement & & & & & & & & -0.01 \\
\hline Parental anxiety & & & & & & & & 0.04 \\
\hline Child sex & & & & & & & & $0.13^{*}$ \\
\hline Age $3 \mathrm{BI} \times 5$-HTTLPR & & & & & & & & $-0.28 *$ \\
\hline
\end{tabular}

Note: BI, Behavioral inhibition; 5-HTTLPR, serotonin transporter linked polymorphic region gene.

$* p<.05 . * * p<.01 . * * * p<.001$

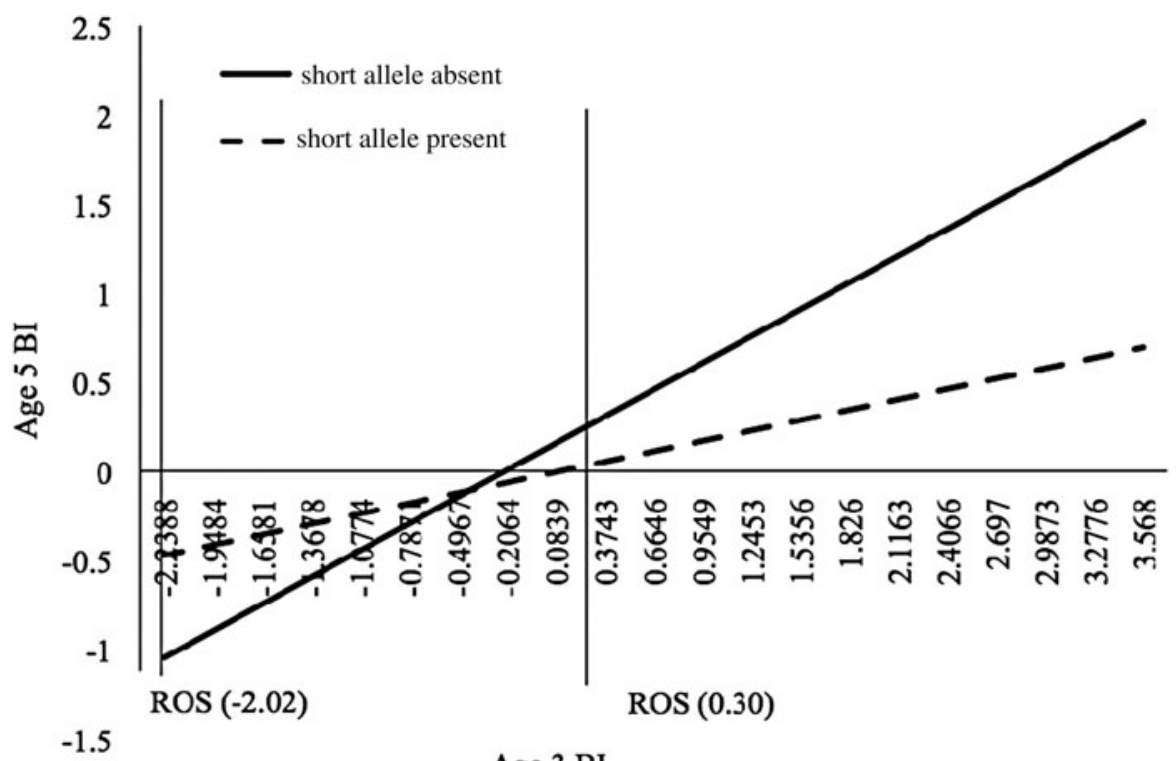

Age 3 BI

Figure 1. Interaction between age 3 behavioral inhibition (BI) and 5-HTTLPR genotype predicting age $5 \mathrm{BI}$ in the parental overinvolvement model. The values $x=-2.02$ and $x=0.30$, derived using the Johnson-Neyman technique (Johnson \& Fay, 1950), indicate the value of age $3 \mathrm{BI}$ above and below which significant differences in age $5 \mathrm{BI}$ emerge for children with and without a copy of the short allele. ROS, Region of significance.

were used. This method uses the asymptotic variances, covariances, and other regression parameters to determine the value(s) of the focal predictor variable at which groups at varying levels of the moderator (e.g., the two levels of a dichotomous moderator variable) are significantly different $(p<.05)$ in terms of the outcome variable. In the present case, such analyses will show which levels of age 3 BI (if any) children with and without a short allele differ in age 5 BI.

Contrary to hypotheses, preliminary models showed that parental overinvolvement and parental anxiety did not inter- act with baseline $\mathrm{BI}$ to predict $\mathrm{BI}$ at follow-up ( $p \mathrm{~s}>.90)$. Thus, the final version of our model included age $3 \mathrm{BI}$, 5-HTTLPR, parental overinvolvement, parental anxiety, and child sex in the first step, followed by the product of age 3 $\mathrm{BI}$ and 5-HTTLPR. The main effects of age $3 \mathrm{BI}$ and child sex were significant in this model (see Table 2). However, the main effect of age $3 \mathrm{BI}$ was qualified by a significant interaction between age $3 \mathrm{BI}$ and 5-HTTLPR. This interaction is depicted in Figure 1. While tests of simple slopes indicated that the relationship between BI at ages 3 and 5 was signifi- 
cant both in the absence $\left(\beta=0.51, p<.0001, r_{\mathrm{p}}=.23\right)$ and presence $\left(\beta=0.20, p<.001, r_{\mathrm{p}}=.18\right)$ of a short allele, the association between age 3 and age 5 BI was stronger in children without a copy of the short allele, consistent with models of differential susceptibility.

Tests of regions of significance (Hayes \& Matthes, 2009) indicated that significant differences in age $5 \mathrm{BI}$ as a function of 5-HTTLPR genotype were evident above a value of 0.30 (i.e., higher than average age $3 \mathrm{BI}$ ) and below a value of -2.02 (i.e., more than two standard deviations below average age $3 \mathrm{BI}$ ). Thus, children with and without a short allele differed in age 5 BI when age 3 BI was higher than average, or when age $3 \mathrm{BI}$ was particularly low. ${ }^{1}$

\section{Discussion}

We drew upon past research highlighting the roles of parenting, parent anxiety, and genetic factors (e.g., Degnan \& Fox, 2007; Fox, Henderson, et al., 2005; Kiel \& Buss, 2012; Moore et al., 2004; Pluess et al., 2010; Rosenbaum et al., 2000; Rubin, Burgess, \& Hastings, 2002) to explore putative influences on the continuity of BI in early childhood. While work has examined mediating influences on the continuity of $\mathrm{BI}$, far less is known about moderators of continuity, an important contribution of this work. We extended previous work by including conceptually related factors (e.g., parental overinvolvement and parental anxiety) in the same model, and used a longitudinal design involving a relatively large sample size. Findings indicated that, of these proposed moderators of BI continuity, 5-HTTLPR genotype was the only significant influence on the association between age 3 and age $5 \mathrm{BI}$, such that the relationship between $\mathrm{BI}$ at ages 3 and 5 was stronger in children without a copy of the short allele. This finding is consistent with past work on the 5-HTTLPR genetic variants in differential susceptibility, in that it suggests the short allele renders children more responsive to influences that lead to greater phenotypic variability over time.

Although studies have examined the influence of 5-HTTLPR on internalizing disorders and temperament in both children and adults (e.g., Burkhouse et al., 2011; Chen et al., 2014; Fox, Henderson, et al., 2005; Liu et al., 2013; Miu, Vulturar, Chiş, Ungureanu, \& Gross, 2013; Verhagen et al., 2009), no research has specifically considered the impact of 5-HTTLPR genotype on the continuity of BI. This def-

1. Maternal and paternal anxiety disorders were collapsed into one parental anxiety variable for purposes of making our model more parsimonious; however, the pattern of findings presented remained similar when examining maternal and paternal anxiety separately. In the model investigating maternal anxiety only, the interaction between age $3 \mathrm{BI}$ and 5-HTTLPR remained significant $(p<.05)$. The same trend was found in the paternal anxiety model $(p=.06)$. Neither maternal nor paternal anxiety significantly interacted with age $3 \mathrm{BI}$ to predict age $5 \mathrm{BI}$ ( $p$ s $=.92$ and .93 , respectively). When a parental depression variable, derived in the same way as the parental anxiety variable, was included as a covariate, results were virtually identical. icit in the literature is surprising given the emerging support for the role of the short allele in differential susceptibility (e.g., Belsky \& Pluess, 2012, 2013; Dalton et al., 2014; Li et al., 2013; Pluess et al., 2010), which indicates that individuals with at least one copy of the short allele have increased receptivity to both positive and negative influences (e.g., Belsky \& Pluess, 2009; Dalton et al., 2014; Ford et al., 2014). Our finding that children with at least one copy of the short allele exhibited less continuity of BI compared to children without the short allele is in line with this emerging literature, possibly because these children are more susceptible to contextual factors that serve to either increase or decrease BI over time.

Differences in age $5 \mathrm{BI}$ based on having a short allele were evident only for children with higher BI at age 3 , and for those with extremely low age $3 \mathrm{BI}$. When children were moderate or somewhat low in age $3 \mathrm{BI}$, the presence or absence of the short allele did not result in differences in age $5 \mathrm{BI}$. Although the reasons for this effect are unclear, of children with a short allele, those with more normative levels of BI may not respond to exposure to novelty as do children with higher BI, if their responses to novelty are already reasonably adaptive. If so, the influence of the putative plasticity allele on BI could be less important. It is also possible that children with a short allele who show more typical levels of BI show evidence of plasticity, but for a different phenotype than BI. In addition, there were differences between children with and without a short allele for age $5 \mathrm{BI}$ when age $3 \mathrm{BI}$ was extremely low, with children without a short allele and low age 3 BI showing especially low levels of age 5 BI. While we did not test this possibility in the current study, it could be that such children will ultimately prove at high risk for externalizing problems, given their especially low inhibition and absence of the short allele, the latter potentially reducing their capacity to adapt to their environments.

Future studies should investigate influences that contribute to the continuity of BI in children with a copy of the short allele. Given cross-sectional and longitudinal research on parenting and BI (e.g., Kiel \& Buss, 2012), as well as parent anxiety and BI, parenting styles (e.g., overprotection or intrusiveness) and parental anxiety are a logical starting point. Unfortunately, we had limited power to explore three-way interactions between age $3 \mathrm{BI}, 5$-HTTLPR genotype, and parent factors, particularly anxiety, in our sample. With regard to parenting, although we did not find interactions between age $3 \mathrm{BI}$ and parenting in the current study, overprotective parenting has been found to moderate observed BI between ages 3 and 6 in other work (Johnson et al., 2016) and mediate BI-related traits between ages 2 and 3 (Kiel \& Buss, 2012). In light of the current findings, it is possible that overprotective parenting may lead to persistently high BI only in children with a copy of the short allele. Concerning parent anxiety, three-way interactions between child BI, 5-HTTLPR, and parental psychopathology may also be useful to investigate in the framework of differential susceptibility hypotheses, particularly given cross-sectional studies on child BI and paren- 
tal internalizing disorders (e.g., Kochanska, 1991; Moehler et al., 2007; Rosenbaum et al., 2000). It is possible that having a parent with an anxiety disorder may impact BI continuity only for children with a copy of the short allele, who may be more genetically responsive to the vulnerability associated with parent anxiety. Future longitudinal research using larger sample sizes will be critical in exploring such three-way interactions, thereby allowing a greater understanding of differential susceptibility in the context of BI continuity in young children.

The possibility of increased susceptibility to context in short allele carriers is particularly important when considering preventative efforts for children with temperamental vulnerability related to BI. Persistently elevated BI has been robustly implicated in anxiety disorder vulnerability (e.g., Chronis-Tuscano et al., 2009; Hirshfeld et al., 1992); therefore, prevention strategies targeting children with high BI who are most likely to remain high in BI over time may be especially cost effective. While replication is needed, our findings suggest that children without a copy of the short allele exhibit greater continuity of BI between the ages of 3 and 5 , thus potentially allowing researchers to further target those most likely to exhibit persistently elevated BI by focusing on children with high BI who do not have a copy of the 5-HTTLPR short allele. Alternatively, children with high BI who have a copy of the short allele may be more responsive to low-cost, minimal interventions given their increased sensitivity to context; thus, it might also prove economical to focus less time-consuming interventions on these children, thereby maximizing distribution of resources.

The lack of significant interactions between age $3 \mathrm{BI}$ and all other proposed moderating variables in the present study is interesting given the current BI literature. In contrast to previous research suggesting that certain negative parenting styles (e.g., overprotection, negativity, or solicitousness) serve to consolidate high BI and BI-related traits in early childhood (e.g., Degnan, Henderson, Fox, \& Rubin, 2008; Hane et al., 2008; Johnson et al., 2016; Kiel \& Buss, 2012; Rubin et al., 2002), we found no influence of parental overinvolvement on the continuity of BI. Several factors may explain this discrepancy. Our participants were from the community, which limited the extent to which more extremely negative parenting styles were evident. In addition, the specific tasks used to assess parenting in this study were not purposely designed to elicit overinvolvement. Furthermore, it is possible that high-risk parenting styles consolidate high child BI over time only for a subset of children, such as those with a copy of the short allele who may possess increased biological sensitivity to context. As previously noted, we did not have adequate power to explore such three-way interactions between parenting, 5-HTTLPR genotype, and age $3 \mathrm{BI}$ in the present study; thus, future research investigating these potential interactions is crucial.

With respect to the lack of association between parental anxiety and the continuity of BI in the current study, it is again important to note that our sample was drawn from the community. Thus, the majority of parents did not have an anxiety disorder, which limited our power to detect interactions between parental anxiety and age $3 \mathrm{BI}$. In addition, the parental anxiety measure used in analyses took into consideration the lifetime diagnosis of any anxiety disorder in parents, in contrast to a current diagnosis. The vast majority of parents were not experiencing an anxiety disorder at the time of the study and may not have experienced an anxiety disorder during their children's lifetime, thereby minimizing children's exposure to the negative sequellae associated with parental anxiety. Had we recruited a clinical sample or focused on parents currently experiencing an anxiety disorder, it is possible that moderating effects of parental anxiety on the relationship between age 3 and age 5 BI would have been found.

\section{Strengths and limitations}

The current study has various strengths. For instance, observational measures of child temperament were used at both baseline and follow-up assessments; observational measures of parental overinvolvement were also used. In addition, the present study used a relatively large sample size (with a respectable retention rate of $90.5 \%$ ) and a longitudinal design that allowed 2 years between baseline and follow-up assessments, thereby permitting a strict test of the continuity of BI. However, several limitations are important to note. First, the current sample size, while larger than most observational, longitudinal studies of BI, did not permit adequate power for exploring three-way interactions between age $3 \mathrm{BI}$, genetic, and contextual factors; such three-way interactions are likely critical to understanding the factors that consolidate BI over time, particularly in children who exhibit biological plasticity. Second, the use of a nonclinical sample may have limited the ability to detect a moderating effect of parental anxiety on the continuity of BI. Third, the sample was comprised primarily of Caucasian participants from middle-class families, restricting the generalizability of this research to other cultures and socioeconomic classes. Several concerns regarding $\mathrm{G} \times \mathrm{E}$ interaction studies are important to note. Complex traits, such as children's BI, are likely to be influenced by multiple genes and multiple environmental factors, such that gene-gene interactions and $\mathrm{G} \times \mathrm{E}$ are at play (e.g., Dick et al., 2015; Riley, 2008); we did not test such complex models in the current study due to limited power. Publication bias is an additional challenge affecting the $\mathrm{G} \times \mathrm{E}$ literature (e.g., Dick et al., 2015). In view of these and other concerns, caution must be exercised when interpreting significant $\mathrm{G} \times \mathrm{E}$ interactions, and replication becomes especially important. Finally, we were unable to explore the role of gene-environment correlation in our models, which may be an important process in understanding how early care and children's BI are related. More specifically, we did not have parental 5-HTTLPR data, which would have allowed us to test associations between caregiver 5-HTTLPR short alleles, early parenting, and the continuity of children's BI.

In summary, our findings suggest that the continuity of BI in early childhood may be shaped partly by 5 -HTTLPR, such 
that differential susceptibility may be at play. Further investigation of contextual factors that may potentially interact with 5-HTTLPR genotype to moderate the continuity of $\mathrm{BI}$ is crucial. Nevertheless, these findings may be relevant in the de-

\section{References}

Abramowitz, J. S., Deacon, B. J., \& Whiteside, S. P. H. (2010). Exposure therapy for anxiety: Principles and practice. New York: Guilford Press.

Aiken, L. S., \& West, S. G. (1991). Multiple regression: Testing and interpreting interactions. Newbury Park, CA: Sage.

Aktar, E., Majdandžić, M., de Vente, W., \& Bögels, S. M. (2013). The interplay between expressed parental anxiety and infant behavioral inhibition predicts infant avoidance in a social referencing paradigm. Journal of Child Psychology and Psychiatry, 54, 144-156.

Andreasen, N. C., Endicott, J., Spitzer, R. L., \& Winokur, G. (1977). The family history method using diagnostic criteria: Reliability and validity. Archives of General Psychiatry, 34, 1229-1235.

Anzman-Frasca, S., Stifter, C. A., \& Birch, L. L. (2012). Temperament and childhood obesity risk: A review of the literature. Journal of Developmental and Behavioral Pediatric, 33, 732-745.

Belsky, J., Jonassain, C., Pluess, M., Stanton, M., Brummett, B., \& Williams, R. (2009). Vulnerability genes or plasticity genes? Molecular Psychiatry, 14, 746-754.

Belsky, J., \& Pluess, M. (2009). Beyond diathesis stress: Differential susceptibility to environmental influences. Psychological Bulletin, 135, 885-908.

Belsky, J., \& Pluess, M. (2012). Differential susceptibility to long-term effects of quality of child care on externalizing behavior in adolescence? International Journal of Behavioral Development, 36, 2-10.

Belsky, J., \& Pluess, M. (2013). Beyond risk, resilience, and dysregulation: Phenotypic plasticity and human development. Development and Psychopathology, 25, 1243-1261.

Biederman, J., Hirshfeld-Becker, D. R., Rosenbaum, J. F., Hérot, C., Friedman, D., Snidman, N., et al. (2001). Further evidence of association between behavioral inhibition and social anxiety in children. American Journal of Psychiatry, 58, 1673-1679.

Boyce, W. T., \& Ellis, B. J. (2005). Biological sensitivity to context: I. An evolutionary-developmental theory of the origins and functions of stress reactivity. Development and Psychopathology, 17, 271-301.

Broberg, A., Lamb, M. E., \& Hwang, P. (1990). Inhibition: Its stability and correlates in sixteen- to forty-month-old children. Child Development, 61, 1153-1163.

Burkhouse, K. L., Gibb, B. E., Coles, M. E., Knopik, V. S., \& McGeary, J. E. (2011). Serotonin transporter genotype moderates the link between children's reports of overprotective parenting and their behavioral inhibition. Journal of Abnormal Child Psychology, 39, 783-790.

Caspi, A., Harrington, H., Milne, B., Amell, J. W., Theodore, R. F., \& Moffit, T. E. (2003). Children's behavioral styles at age 3 are linked to their adult personality traits at age 26. Journal of Personality, 71, 495-513.

Chen, X., Chen, H., Li, D., \& Wang, L. (2009). Early childhood behavioral inhibition and social and school adjustment in Chinese children: A 5-year longitudinal study. Child Development, 80, 1692-1704.

Chen, X., Zhang, G., Liang, Z., Zhang, M., Way, N., Yoshikawa, H., et al. (2014). The association between 5-HTTLPR gene polymorphism and behavioral inhibition in Chinese toddlers. Developmental Psychobiology, $56,1601-1608$.

Chronis-Tuscano, A., Degnan, K. A., Pine, D. S., Perez-Edgar, K., Henderson, H. A., Diaz, Y., et al. (2009). Stable early maternal report of behavioral inhibition predicts lifetime social anxiety disorder in adolescence. Journal of the American Academy of Child \& Adolescent Psychiatry, 48, 928-935.

Clauss, J. A., \& Blackford, J. U. (2012). Behavioral inhibition and risk for developing social anxiety disorder: A meta-analytic study. Journal of the American Academy of Child \& Adolescent Psychiatry, 51, 10661075.

Coles, M. E., Schofield, C. A., \& Pietrefesa, A. S. (2006). Behavioral inhibition and obsessive-compulsive disorder. Journal of Anxiety Disorders, $20,1118-1132$

Cox, M., \& Crnic, K. (2003). Qualitative ratings for parent-child interaction at 3-15 months. Unpublished manuscript, University of North Carolina at Chapel Hill, Center for Coding Science.

Dalton, E. D., Hammen, C. L., Najman, J. L., \& Brennan, P. A. (2014). Genetic susceptibility to family environment: BDNF Val66met and velopment and implementation of targeted prevention strategies for children at increased vulnerability for negative outcomes (e.g., anxiety disorders) related to BI in early childhood.

5-HTTLPR influence depressive symptoms. Journal of Family Psychology, 28, 947-956.

Degnan, K. A., \& Fox, N. A. (2007). Behavioral inhibition and anxiety disorders: Multiple levels of a resilience process. Development and Psychopathology, 19, 729-746.

Degnan, K. A., Henderson, H. A., Fox, N. A., \& Rubin, K. H. (2008). Predicting social wariness in middle childhood: The moderating roles of child care history, maternal personality and maternal behavior. Social Development, $17,471-487$.

Dick, D. M., Agrawal, A., Keller, M. C., Adkins, A. A., Aliev, F., Monroe, S., et al. (2015). Candidate gene-environment interaction research: Reflections and recommendations. Perspectives on Psychological Science, $10,37-59$.

Doey, L., Coplan, R. J., \& Kingsbury, M. (2014). Bashful boys and coy girls: A review of gender differences in childhood shyness. Sex Roles, 70, 255-266.

Dunn, L. M., \& Dunn, L. M. (1997). Peabody Picture Vocabulary Test (3rd ed.). Circle Pines, MN: American Guidance Service.

Durbin, C. E., Klein, D. N., Hayden, E. P., Buckley, M. E., \& Moerk, K. C. (2005). Temperamental emotionality in preschoolers and parental mood disorders. Journal of Abnormal Psychology, 114, 28-37.

Egeland, B., Weinfield, N., Hiester, M., Lawrence, C., Pierce, S., \& Chippendale, K. (1995). Teaching tasks administration and scoring manual. Unpublished manuscript, University of Minnesota.

Essex, M. J., Klein, M. H., Slattery, M. H. J., Goldsmith, H. H., \& Kalin, N. H. (2010). Early risk factors and developmental pathways to chronic high inhibition and social anxiety disorder in adolescence. American Journal of Psychiatry, 167, 40-46.

First, M. B., Gibbon, M., Spitzer, R. L., \& Williams, J. B. W. (1996). The Structured Clinical Interview for DSM-IVAxis I Disorders: Non-patient edition (SCID-I, Version 2.0). New York: New York State Psychiatric Institute, Biometrics Research Department.

Ford, B. Q., Mauss, I. B., Troy, A. S., Smolen, A., \& Hankin, B. (2014). Emotion regulation moderates the risk associated with the 5-HTT gene and stress in children. Emotion, 14, 930-939.

Fox, N. A., Henderson, H. A., Marshall, P. J., Nichols, K. E., \& Ghera, M. M. (2005). Behavioral inhibition: Linking biology and behavior within a developmental framework. Annual Review of Psychology, 56, 235-262.

Fox, N. A., Nichols, K. E., Henderson, H. A., Rubin, K., Schmidt, L., Hamer, D., et al. (2005). Evidence for a gene-environment interaction in predicting behavioral inhibition in middle childhood. Psychological Science, 16, 921-926.

Franić, S., Middeldorp, C. M., Dolan, C. V., Ligthart, L., \& Boomsma, D. I (2010). Childhood and adolescent anxiety and depression: Beyond heritability. Journal of the American Academy of Child \& Adolescent Psychiatry, 49, 820-829.

Garcia, S. E., Tully, E. C., Tarantino, N., South, S., Iacono, W. G., \& McGue, M. (2013). Changes in genetic and environmental influences on trait anxiety from middle adolescence to early adulthood. Journal of Affective Disorders, 151, 46-53.

Garcia-Coll, C., Kagan, J., \& Reznick, J. S. (1984). Behavioral inhibition in young children. Child Development, 55, 1005-1019.

Gest, S. D. (1997). Behavioral inhibition: Stability and associations with adaptation from childhood to early adulthood. Journal of Personality and Social Psychology, 72, 467-475.

Gladstone, G. L., Parker, G. B., Mitchell, P. B., Wilhelm, K. A., \& Malhi, G. S. (2005). Relationship between self-reported childhood behavioral inhibition and lifetime anxiety disorders in a clinical sample. Depression and Anxiety, 22, 103-113.

Goldsmith, H. H., Reilly, J., Lemery, K. S., Longley, S., \& Prescott, A. (1995). Laboratory Temperament Assessment Battery: Preschool version. Unpublished manuscript.

Graham, A. A., \& Coplan, R. J. (2012). Shyness, sibling relationships, and young children's socioemotional adjustment at preschool. Journal of Research in Childhood Education, 26, 435-449.

Hane, A. A., Cheah, C., Rubin, K. H., \& Fox, N. A. (2008). The role of maternal behavior in the relation between shyness and social reticence in 
early childhood and social withdrawal in middle childhood. Social Development, 17, 795-811.

Hayes, A. F., \& Matthes, J. (2009). Computational procedures for probing interactions in OLS and logistic regression: SPSS and SAS implementations. Behavior Research Methods, 41, 924-936.

Hayward, C., Killen, J. D., Kraemer, H. C., \& Taylor, C. B. (1998). Linking self-reported childhood behavioral inhibition to adolescent social phobia. Journal of the American Academy of Child \& Adolescent Psychiatry, 37, 1308-1316.

Hirshfeld, D. R., Rosenbaum, J. F., Biederman, J., Bolduc, E. A., Faraone, S. V., Snidman, N., et al. (1992). Stable behavioral inhibition and its association with anxiety disorder. Journal of the American Academy of Child \& Adolescent Psychiatry, 31, 103-111.

Hirshfeld-Becker, D. R., Biederman, J., Henin, A., Faraone, S. V, Davis, S., Harrington, K., et al. (2007). Behavioral inhibition in preschool children at risk is a specific predictor of middle childhood social anxiety: A fiveyear follow-up. Journal of Developmental and Behavioral Pediatrics, 28, 225-233.

Hirshfeld-Becker, D. R., Micco, J., Henin, A., Bloomfield, A., Biederman, J., \& Rosenbaum, J. (2008). Behavioral inhibition. Depression and Anxiety, $25,357-367$.

Hubert, N. C., Wachs, T. D., Peters-Martin, P., \& Gandour, M. J. (1982). The study of early temperament: Measurement and conceptual issues. Child Development, 53, 571-600.

Ipsa, J. M., Fine, M. A., Halgunseth, L. C., Harper, S., Robinson, J., Boyce, L., et al. (2004). Maternal intrusiveness, maternal warmth, and mothertoddler relationship outcomes: Variations across low income ethnic and acculturation groups. Child Development, 75, 1613-1631.

Izard, C. E., Schultz, D., Fine, S. E., Youngstrom, E., \& Ackerman, B. P. (1999). Temperament, cognitive ability, emotion knowledge, and adaptive social behavior. Imagination, Cognition, and Personality, 19, 305-330.

Johnson, P. O., \& Fay, L. C. (1950). The Johnson-Neyman technique, its theory and application. Psychometrika, 15, 349-367.

Johnson, V. C., Olino, T. M., Klein, D. N., Dyson, M. W., Bufferd, S. J., Durbin, C. E., et al. (2016). A longitudinal investigation of predictors of the stability of behavioral inhibition in early childhood. Manuscript submitted for publication.

Kagan, J. (1997). Temperament and the reactions to unfamiliarity. Child Development, 68, 139-143.

Kagan, J. (2003). Behavioral inhibition as a temperamental category. In R. J. Davidson, K. R. Scherer, \& H. H. Goldsmith (Eds.), Handbook of affective sciences (pp. 320-331). New York: Oxford University Press.

Kagan, J., \& Moss, H. A. (1962). Birth to maturity. New York: Wiley.

Kagan, J., Reznick, J. S., Clarke, C., Snidman, N., \& Garcia-Coll, C. (1984). Behavioral inhibition to the unfamiliar. Child Development, 55, 22122225.

Kagan, J., Reznick, J. S., \& Snidman, N. (1988). Biological bases of childhood shyness. Science, 240, 167-171.

Kagan, J., Reznick, J. S., \& Snidman, N., Gibbons, J., \& Johnson, M. O. (1988). Childhood derivatives of inhibition and lack of inhibition to the unfamiliar. Child Development, 59, 1580-1589.

Kerr, M., Lambert, W. W., Stattin, H., \& Klackenberg-Larsson, I. (2014). Stability of inhibition in a Swedish longitudinal Sample. Child Development, 65, 138-146.

Kiel, E. J., \& Buss, K. A. (2012). Associations among context-specific maternal protective behavior, toddlers' fearful temperament, and maternal accuracy and goals. Social Development, 21, 742-760.

Kochanska, G. (1991). Patterns of inhibition to the unfamiliar in children of normal and affectively ill mothers. Child Development, 62, 250-263.

Lahat, A., Hong, M., \& Fox, N. A. (2011). Behavioral inhibition: Is it a risk factor for anxiety? International Review of Psychiatry, 23, 248-257.

Lamb, D. J., Middeldorp, C. M., van Beijsterveldt, C. E. M., Bartels, M., van der Aa, N., Polderman, T. J. C., et al. (2010). Heritability of anxious-depressive and withdrawn behavior: Age-related changes during adolescence. Journal of the American Academy of Child \& Adolescent Psychiatry, 49, 248-255.

Lanzenberger, R. R., Mitterhauser, M., Spindelegger, C., Wadsak, W., Klein, N., Mien, L., et al. (2007). Reduced serotonin-1A receptor binding in social anxiety disorder. Biological Psychiatry, 61, 1081-1089.

Laptook, R. S., Klein, D. N., Durbin, C. E., Hayden, E. P., Olino, T. M., \& Carlson, G. (2008) Differentiation between low positive affectivity and behavioral inhibition in preschool-age children: A comparison of behavioral approach in novel and non-novel contexts. Personality and Individual Differences, 44, 758-767.
Laptook, R. S., Klein, D. N., Olino, T. M., Dyson, M. W., \& Carlson, G (2010). Low positive affectivity and behavioral inhibition in preschoolage children: A replication and extension of previous findings. Personality and Individual Differences, 48, 547-551.

Lewis-Morrarty, E., Degnan, K. A., Chronis-Tuscano, A., Rubin, K. H., Cheah, C. S. L., Pine, D. S., et al. (2012). Maternal over-control moderates the association between early childhood behavioral inhibition and adolescent social anxiety symptoms. Journal of Abnormal Child Psychology, 40, 1363-1373.

Li, J. J., Berk, M. S., \& Lee, S. S. (2013). Differential susceptibility in longitudinal models of gene-environment interaction for adolescent depression. Development and Psychopathology, 25, 991-1003.

Liu, B., Lavebratt, C., Nordqvist, T., Fandiño-Losada, A., Theorell, T., Forell, Y., et al. (2013). Working conditions, serotonin transporter gene polymorphism (5-HTTLPR) and anxiety disorders: A prospective cohort study. Journal of Affective Disorders, 151, 652-659.

Liu, R. T. (2015). A developmentally informed perspective on the relation between stress and psychopathology: When the problem with stress is that there is not enough. Journal of Abnormal Psychology, 124, 8092.

Mackrell, S. V. M., Sheikh, H. I., Kotelnikova, Y., Kryski, K. R., Jordan, P. L., Singh, S. M., et al. (2014). Child temperament and parental depression predict cortisol reactivity to stress in middle childhood. Journal of Abnormal Psychology, 123, 106-116.

McCrae, R. R., Costa, P. T. J., Ostendorf, F., Angleitner, A., Hřebičková, M., Avia, M. D., et al. (2000). Nature over nurture: Temperament, personality, and life span development. Journal of Personality and Social Psychology, 78, 173-186.

Miu, A., Vulturar, R., Chiş, A., Ungureanu, L., \& Gross, J. J. (2013). Reappraisal as a mediator in the link between 5-HTTLPR and social anxiety symptoms. Emotion, 13, 1012-1022.

Moehler, E., Kagan, J., Parzer, P., Brunner, R., Reck, C., Wiebel, A., et al. (2007). Childhood behavioral inhibition and maternal symptoms of depression. Psychopathology, 40, 446-452.

Moore, P. S., Whaley, S. E., \& Sigman, M. (2004). Interactions between mothers and children: Impacts of maternal and child anxiety. Journal of Abnormal Psychology, 113, 471-476.

Muris, P., Meesters, C., \& Spinder, M. (2003). Relationships between childand parent-reported behavioral inhibition and symptoms of anxiety and depression in normal adolescents. Personality and Individual Differences, 34, 759-771.

Muris, P., Merckelbach, H., Schmidt, H., Gadet, B., \& Bogie, N. (2001). Anxiety and depression as correlates of self-reported behavioral inhibition in normal adolescents. Behavior Research and Therapy, 39, 1051-1061.

Muris, P., van Brakel, A. M. L., Arntz, A., \& Schouten, E. (2011). Behavioral inhibition as a risk factor for the development of childhood anxiety disorders: A longitudinal study. Journal of Child and Family Studies, 20, 157-170.

Murphy, S. E., Norbury, R., Godlewska, B. R., Cowen, P. J., Mannie, Z. M., Harmer, C. J., et al. (2013). The effect of the serotonin transporter polymorphism (5-HTTLPR) on amygdala function: A meta-analysis. Molecular Psychiatry, 18, 512-520.

National Institute of Child Health and Human Development Early Child Care Research Network. (1997). The effects of infant child care on infantmother attachment security: Results of the NICHD Study of Early Child Care. Child Development, 68, 860-879.

Natsuaki, M. N., Leve, L. D., Neiderhiser, J. M., Shaw, D. S., Scarmella, L. V., Ge, X., et al. (2013). Intergenerational transmission of risk for social inhibition: The interplay between parental responsiveness and genetic influences. Development and Psychopathology, 25, 261-274.

Ohara, K., Nagai, M., Suzuki, Y., Ochiai, M., \& Ohara, K. (1998). Association between anxiety disorders and a functional polymorphism in the serotonin transporter gene. Psychiatry Research, 81, 277-279.

Olino, T. M., Klein, D. N., Dyson, M. W., Rose, S. A., \& Durbin, C. E. (2010). Temperamental emotionality in preschool-aged children and depressive disorders in parents: Associations in a large community sample. Journal of Abnormal Psychology, 119, 468-478.

Oppenheimer, C. W., Hankin, B. L., Young, J. F., \& Smolen, A. (2013) Youth genetic vulnerability to maternal depressive symptoms: 5-HTTLPR as moderator of intergenerational transmission effects in a multiwave prospective study. Depression and Anxiety, 30, 190-196.

Pluess, M., \& Belsky, J. (2009). Differential susceptibility to rearing experience: The case of childcare. Journal of Child Psychology and Psychiatry, $50,396-404$. 
Pluess, M., Belsky, J., Way, B. M., \& Taylor, S. E. (2010). 5-HTTLPR moderates effects of current life events on neuroticism: Differential susceptibility to environmental influences. Progress in Neuropsychopharmacology \& Biological Psychiatry, 34, 1070-1074.

Riley, B. P. (2008). Commentary on "the case for gene-environment interactions in psychiatry." Current Opinion in Psychiatry, 21, 324-325.

Robinson, J. L., Kagan, J., Reznick, J. S., \& Corley, R. (1992). The heritabliity of inhibited and uninhibited behavior: A twin study. Developmental Psychology, 28, 1030-1037.

Rogers, J., Shelton, S. E., Shelledy, W., Garcia, R., \& Kalin, N. H. (2008). Genetic influences on behavioral inhibition and anxiety in juvenile rhesus macaques. Genes, Brain and Behavior, 7, 463-469.

Root, A. K., \& Stifter, C. (2010). Temperament and maternal emotion socialization beliefs as predictors of early childhood social behavior in the laboratory and classroom. Parenting: Science and Practice, 10, 241-257.

Rosenbaum, J. F., Beiderman, J., Hirshfeld, D. R., Bolduc, E. A., \& Chaloff, J. (1991). Behavioral inhibition in children: A possible precursor tor panic disorder or social phobia. Journal of Clinical Psychiatry, 52, 5-9.

Rosenbaum, J. F., Beiderman, J., Hirshfeld-Becker, D. R., Kagan, J., Snidman, N., Friedman, D., et al. (2000). A controlled study of behavioral inhibition in children of parents with panic disorder and depression. American Journal of Psychiatry, 157, 2002-2010.

Roswell, H. C., \& Coplan, R. J. (2013). Exploring links between shyness, romantic relationship quality, and well-being. Canadian Journal of Behavioral Science, 45, 287-295.

Rotge, J.-Y., Grabot, D., Aouizerate, B., Pélissolo, A., Lépine, J.-P., \& Tignol, J. (2011). Childhood history of behavioral inhibition and comorbidity status in 256 adults with social phobia. Journal of Affective Disorders, 129, 338-341.

Rothbart, M. K. (1989). Temperament in childhood: A framework. In G. A. Kohnstamm, J. A. Bates, \& M. K. Rothbart (Eds.), Temperament in childhood (pp. 59-73). New York: Wiley.

Rothbart, M. K., Ahadi, S. A., \& Evans, D. E. (2000). Temperament and personality: Origins and outcomes. Journal of Personality and Social Psychology, 78, 122-135.

Rothbart, M. K., \& Derryberry, D. (1981). Development of individual differences in temperament. Advances in Developmental Psychology, 1, 37-46.

Rubin, D. H., Althoff, R. R., Ehli, E. A., Davies, G. E., Rettew, D. C., Crehan, E. T., et al. (2013). Candidate gene associations with withdrawn behavior. Journal of Child Psychology and Psychiatry, 54, 1337-1345.

Rubin, K. H., Burgess, K. B., \& Hastings, P. D. (2002). Stability and socialbehavioral consequences of toddlers' inhibited temperament and parenting behaviors. Child Development, 73, 483-495.
Rubin, K. H., Hastings, P. D., Stewart, S. L., Henderson, H. A., \& Chen, X. (1997). The consistency and concomitants of inhibition: Some of the children, all of the time. Child Development, 68, 467-483.

Rutter, M. (2012). Resilience as a dynamic concept. Development and Psychopathology, 24, 335-344.

Scarpa, A., Raine, A., Venables, P. H., \& Mednick, S. A. (1995). The stability of inhibited/uninhibited temperament from ages 3 to 11 years in Mauritian children. Journal of Abnormal Child Psychology, 23, 607-618.

Schinka, J. A., Busch, R. M., \& Robichaux-Keene, N. (2004). A meta-analysis of the association between the serotonin transporter gene polymorphism (5-HTTLPR) and trait anxiety. Molecular Psychiatry, 9, 197-202.

Schwartz, C. E., Wright, C. I., Shin, L. M., Kagan, J., \& Rauch, S. L. (2003). Inhibited and uninhibited infants "grown up": Adult amygdalar response to novelty. Science, 300, 1952-1953.

Sheikh, H. I., Hayden, E. P., Kryski, K. R., Smith, H. J., \& Singh, S. M. (2010). Genotyping the BDNF rs6265 (val66met) polymorphism by one-step amplified refractory mutation system PCR. Psychiatric Genetics, 20, 109-112.

Van den Akker, A. L., Deković, M., Prinzie, P., \& Asscher, J. J. (2010). Toddlers' temperament profiles: Stability and relations to negative and positive parenting. Journal of Abnormal Child Psychology, 38, 485-495.

Verhagen, M., van der Meij, A., van Deurzen, P. A. M., Janzing, J. G. E., AriasVásquez, A., Buitelaar, J. K., et al. (2009). Effect of the 5-HTTLPR polymorphism in the serotonin transporter gene on major depressive disorder and related comorbid disorders. Psychiatric Genetics, 19, 39-44.

Vreeke, L. J., Muris, P., Mayer, B., Huijding, J., \& Rapee, R. (2013). Skittish, shielded, and scared: Relations among behavioral inhibition, overprotective parenting, and anxiety in native and non-native Dutch preschool children. Journal of Anxiety Disorders, 27, 703-710.

Weinfield, N. S., Egeland, B., \& Ogawa, J. R. (1998). Promises to keep: Assessing affective and behavioral qualities of mother-child relationships in the New Chance Observational Study. Working Paper: Child Development. Chicago: Northwestern University and University of Chicago, Joint Center for Poverty Research.

Whaley, S. E., Pinto, A., \& Sigman, M. (1999). Characterizing interactions between anxious mothers and their children. Journal of Consulting and Clinical Psychology, 67, 826-836.

Woodruff-Borden, J., Morrow, C., Bourland, S., \& Cambron, S. (2002). The behavior of anxious parents: Examining mechanisms of transmission of anxiety from parent to child. Journal of Clinical Child and Adolescent Psychology, 31, 364-374.

Wu, G., Feder, A., Cohen, H., Kim, J. J., Calderon, S., Charney, D. S., et al. (2013). Understanding resilience. Frontiers in Behavioral Neuroscience, 7, 1-15. 